\title{
ADAMTS1 and MMP1 proteolytically engage EGF-like ligands in an osteolytic signaling cascade for bone metastasis
}

\author{
Xin Lu, ${ }^{1}$ Qiongqing Wang, ${ }^{2}$ Guohong Hu, ${ }^{1}$ Catherine Van Poznak, ${ }^{3,7}$ Martin Fleisher, ${ }^{4}$ Michael Reiss, ${ }^{5}$ \\ Joan Massagué, ${ }^{2,6}$ and Yibin Kang, ${ }^{1,5,8}$ \\ ${ }^{1}$ Department of Molecular Biology, Princeton University, Princeton, New Jersey 08544, USA; ${ }^{2}$ Cancer Biology and Genetics \\ Program, Memorial Sloan-Kettering Cancer Center, New York, New York 10021, USA; ${ }^{3}$ Department of Medicine, Memorial \\ Sloan-Kettering Cancer Center, New York, New York 10021, USA; ${ }^{4}$ Department of Clinical Laboratories, Memorial Sloan- \\ Kettering Cancer Center, New York, New York 10021, USA; ${ }^{5}$ Breast Cancer Program, Cancer Institute of New Jersey, New \\ Brunswick, New Jersey 08903, USA; ${ }^{6}$ Howard Hughes Medical Institute, Memorial Sloan-Kettering Cancer Center, New York, \\ New York 10021, USA
}

Bone metastasis is mediated by complex interactions between tumor cells and resident stromal cells in the bone microenvironment. The functions of metalloproteinases in organ-specific metastasis remain poorly defined despite their well-appreciated role in matrix degradation and tumor invasion. Here, we show a mechanism whereby two distinct metalloproteinases, a disintegrin and metalloproteinase with thrombospondin motifs (ADAMTS1) and matrix metalloproteinase-1 (MMP1), orchestrate a paracrine signaling cascade to modulate the bone microenvironment in favor of osteoclastogenesis and bone metastasis. Proteolytic release of membranebound epidermal growth factor (EGF)-like growth factors, including Amphiregulin (AREG), heparin-binding EGF (HB-EGF), and transforming growth factor $\alpha$ (TGF $\alpha$ ) from tumor cells suppress the expression of osteoprotegerin (OPG) in osteoblasts and subsequently potentiate osteoclast differentiation. EGF receptor (EGFR) inhibitors block osteolytic bone metastasis by targeting EGFR signaling in bone stromal cells. Furthermore, elevated MMP1 and ADAMTS1 expression is associated with increased risk of bone metastasis in breast cancer patients. This study established MMP1 and ADAMTS1 in tumor cells, as well as EGFR signaling in osteoblasts, as promising therapeutic targets for inhibiting bone metastasis of breast cancer.

[Keywords: EGFR; bone metastasis; breast cancer; metalloprotease; osteoclastogenesis]

Supplemental material is available at http://www.genesdev.org.

Received May 25, 2009; revised version accepted June 22, 2009.

Bone metastasis is a frequent complication of breast cancer, and is often accompanied by debilitating bone fracture, severe pain, nerve compression, and hypercalcemia (Mundy 2002; Roodman 2004; Guise et al. 2005; Gupta and Massague 2006). Effective therapies for bone metastases rely on a better molecular understanding of the pathological process. An important concept has emerged in recent years that osteolytic bone metastasis is driven by intricate cellular and molecular interactions among tumor cells and host stromal cells commonly found in the bone milieu (Mundy 2002; Roodman 2004; Guise et al. 2005). Tumor-derived factors alter the fine balance of osteoclast and osteoblast activities that are

\footnotetext{
${ }^{7}$ Present address: Department of Internal Medicine, University of Michigan, Ann Arbor, MI 48109, USA.

${ }^{8}$ Corresponding author.

E-MAIL ykang@princeton.edu; FAX (609) 258-2340.

Article published online ahead of print. Article and publication date are online at http://www.genesdev.org/cgi/doi/10.1101/gad.1824809
}

necessary for maintaining normal bone homeostasis. Increased osteoclast activity leads to bone matrix degradation and the release of bone-derived growth factors that can further stimulate the metastatic function of tumor cells. Central to the control of this so-called "vicious cycle" of bone metastasis is the modulation of osteoclast activity by the tumor necrosis factor (TNF) family member receptor activator of nuclear $\mathrm{\kappa B}$ ligand (RANKL) (Mundy 2002). RANKL is expressed in both membranebound and soluble forms by osteoblasts, while its cognate receptor RANK is expressed on the surface of osteoclasts and controls a key signaling pathway essential for osteoclast differentiation. Osteoprotegerin (OPG), a soluble decoy receptor of RANKL, is also produced by osteoblasts to antagonize the activity of RANKL. The function of tumor-derived bone metastasis factors, such as parathyroid hormone-related peptide (PTHrP), hinges upon their ability to increase RANKL production or decrease OPG secretion by osteoblasts, ultimately promoting osteoclast differentiation and activation (Mundy 2002). 
Although metalloproteinases are well known to have critical functions in tissue remodeling, tumor progression, and metastasis through their proteolytic activities for extracellular matrix (ECM) degradation, invasion, and cytokine mobilization (Egeblad and Werb 2002; Overall and Lopez-Otin 2002; Page-McCaw et al. 2007), the specific functional mechanism of metalloproteinases in promoting bone metastasis has not been well characterized. In an attempt to identify breast cancer bone metastasis genes, we previously used an in vivo selection approach to derive highly bone metastatic variants from the MDA-MB-231 breast cancer cell line (Kang et al. 2003). Gene expression profiling of these variants identified a set of 11 putative breast cancer bone metastasis genes, including two genes encoding metalloproteinases, a disintegrin and metalloproteinase with thrombospondin motifs (ADAMTS1) and matrix metalloproteinase-1 (MMP1). Thus, this model system provides an ideal opportunity to explore the functional role of these two metalloproteinases in bone metastasis.

ADAMTS1, a member of the ADAMTS family (Kuno et al. 1997), has been shown to be capable of binding to and degrading ECM components, including the proteoglycans aggrecan and versican (Porter et al. 2005). Overexpression of ADAMTS1 promotes pulmonary metastasis of TA3 mammary carcinoma and Lewis lung carcinoma cells (Liu et al. 2005). However, the functional and clinical relevance of ADAMTS1 in bone metastasis remains unknown. MMP1 (also known as interstitial collagenase) is the prototype of the large family of MMPs (Page-McCaw et al. 2007). Although the main substrates of MMP1 are fibrillar collagens, it can cleave many other components in the ECM, including perlecan, laminin, aggrecan, and versican, some of which are also substrates for ADAMTS1. Additionally, signaling molecule precursors, such as pro-TNF $\alpha$, can be shed from cell surface by MMP1 (McCawley and Matrisian 2001; Egeblad and Werb 2002). MMP1 overexpression was found in a wide variety of malignant tumors (Brinckerhoff et al. 2000; Egeblad and Werb 2002) and was almost invariably correlated with increased tumor stage, presence of distant metastasis, and poor survival (Egeblad and Werb 2002). In addition to its ability to degrade ECM, MMP1 can also promote tumor invasion through proteolytic activation of G protein coupled receptor PAR1 (Boire et al. 2005). Despite the well-known function of MMP1 in tumor progression, its role in bone metastasis has remained undefined.

In this study, we uncovered a functional role of MMP1 and ADAMTS1 in promoting osteolytic bone metastasis. The combined actions of these two proteases activate osteoclast differentiation by shedding tumor-derived epidermal growth factor (EGF)-like factors to reduce osteoblast production of OPG in the local bone microenvironment. EGF receptor (EGFR) inhibitors block osteolytic bone metastasis by targeting EGFR signaling in bone stromal cells, and therefore may have therapeutic benefits in the treatment of bone metastasis even for patients whose primary tumors are nonresponsive to EGFR inhibitors. Simultaneous overexpression of MMP1 and ADAMTS1 were observed in a large proportion of breast tumor samples and is associated with increased risk of bone metastasis. These results suggest that molecular targeting of metalloproteinases and EGFR signaling in the bone stroma may become effective therapeutics for breast cancer bone metastasis.

\section{Results}

Combined silencing of ADAMTS1 and MMP1 reduces bone metastasis

Northern blot analysis of MDA-MB-231 sublines with different metastasis abilities to bone revealed that ADAMTS1 and/or $M M P 1$ were highly expressed only in the highly metastatic sublines (Fig. 1A; Kang et al. 2003; Minn et al. 2005a). In order to test the functional importance of ADAMTS1 and MMP1 in metastasis, the expression of these two genes was silenced either individually or in combination by sshRNAs in SCP20, a highly bone metastatic single-cell-derived progeny (SCP) from MDAMB-231 (Fig. 1B; Kang et al. 2003). The control and knockdown derivatives of SCP20 were inoculated into nude mice by intracardiac injection, and metastasis burden was measured by weekly bioluminescence imaging (BLI) using a firefly luciferase reporter stably expressed in these cells (Minn et al. 2005b). Kaplan-Meier curves and normalized BLI signals were plotted to analyze the kinetics of the metastasis development (Fig. 1C; Supplemental Fig. S1A,B). Whereas the single knockdown of either ADAMTS1 or MMP1 did not significantly reduce the incidence of bone metastases or prolong survival $(P>0.1)$, the combined silencing of both genes dramatically inhibited bone metastasis formation $(P=0.0041)$ (Fig. 1C) and increased the survival rate $(P=0.0037)$ (Supplemental Fig. S1A). As indicated by BLI signal curves, the single knockdowns caused an appreciable reduction of metastasis burden, yet a highly significant reduction was observed only when the expression of both genes was silenced (Supplemental Fig. S1B; representative mice from each group are shown in Fig. 1D). $\mathrm{X}$-ray imaging revealed extensive osteolytic bone lesions formed by the control and single-knockdown cells, whereas mice injected with double-knockdown cells maintained their bone integrity (Fig. 1D). The osteolytic nature of the metastases was confirmed by hematoxylin and eosin (H\&E) staining, and the presence of osteoclasts along the tumor-bone interface was visualized and quantified by tartrate-resistant acid phosphatase (TRAP) staining (Fig. 1D; Supplemental Fig. S2 for enlarged images). Consistent with the pattern of the reduction in metastasis burden by single and double knockdowns revealed by BLI, osteoclast number was highest in the control group and significantly lower in the knockdown groups, with the most dramatic reduction observed in the double-knockdown group (Fig. 1E; Supplemental Fig. S2). In the rare bone metastases developed in mice inoculated with the double knockdown cells, the bone lesions had a smooth tumor-bone interface and very few TRAP-positive cells (Fig. 1D,E). Most of 
Lu et al.

A

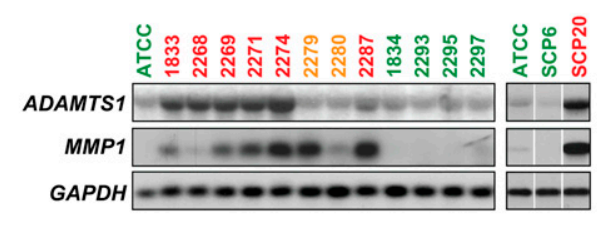

B

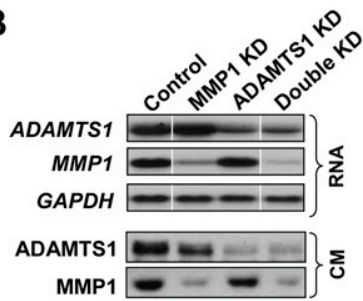

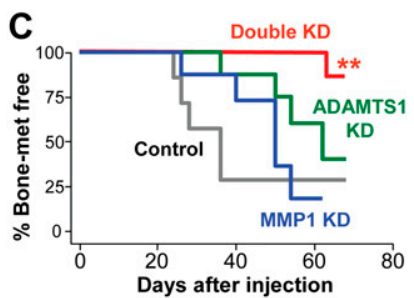

D
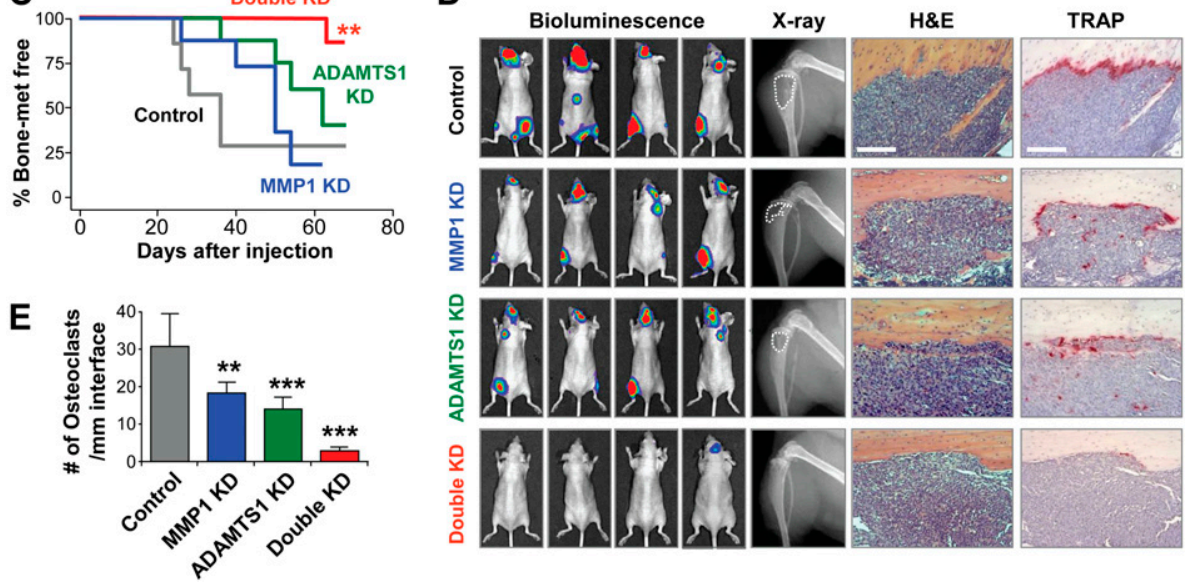

Figure 1. Inhibition of breast cancer bone metastasis by combined knockdown of ADAMTS1 and MMP1. (A) Northern blot analysis of ADAMTS1 and MMP1 expression in MDA-MB-231 derivatives with different bone metastasis abilities (Kang et al. 2003). ATCC denotes the parental MDA-MB-231 cell line. Sublines designated by four-digit numbers were obtained from in vivo selection of MDA-MB-231. SCP6 and SCP20 were SCPs of MDA-MB-231 derived in vitro by dilution cloning. Sublines are color-coded for their previously reported metastatic ability to bone: strong (red), intermediate (orange), and weak (green) (Kang et al. 2003). (B) Effective knockdown of ADAMTS1 and MMP1 in the MDA-MB-231 subline SCP20 was confirmed by Northern blot analysis of total RNA or Western blot analysis of the CM. In $A$ and $B$, white dividing lines separating lanes denote grouping of images from different parts of the same gel. (C) Kaplan-Meier curve of the incidence of bone metastases in the hindlimbs of the nude mice after intracardiac injection of various cell lines, including SCP20 stably infected with control viruses, or viruses expressing MMP1 shRNA, ADAMTS1 shRNA, or both. $n=10$. $\left(^{\star \star}\right) P<0.01$ based on log-rank test. $(D)$ Bioluminescent (BLI), radiographic and histological (H\&E and TRAP staining) analyses of bone lesions in four representative mice of each experimental group at day 50 after cell injection. The BLI images are shown under the same color scale. In the radiograph images, white dotted lines show the contour of the bone lesions. Rare small bone metastasis observed in mice injected with double-knockdown cells has smooth tumor-bone interface and very few TRAP-positive cells. Bars, $200 \mu \mathrm{m}$. $(E)$ Quantification of TRAP-positive osteoclasts along the tumor-bone interface. Data represent average \pm SD. $\left(^{\star \star}\right) P<0.01 ;\left(^{\star \star \star}\right) P<0.001$ based on twosided Student's $t$-test.

small bone lesions developed by double-knockdown cell regressed a few days after detection by BLI (see example in Supplemental Fig. S1C). ADAMTS1 and MMP1 do not play a direct role in the proliferation of tumor cells, as no significant difference in primary tumor growth was observed for all three knockdown lines compared with the control line after mammary fat pad injection $(P>0.4)$ (Supplemental Fig. S1D). This was consistent with a recent report revealing no correlation between MMP1 mRNA level and tumor size in breast cancer (Cheng et al. 2008). To rule out the possibility that the metastatic behavior changes observed in the knockdown cells could be due to nonspecific gene silencing, we rescued the expression of ADAMTS1 and MMP1, either individually or simultaneously, in the double-knockdown cells by stably expressing shRNA-resistant coding sequences (Supplemental Fig. S3A). When the modified cells were evaluated for the bone metastasis ability, rescue of either ADAMTS1 or MMP1 expression to the level of the orig- inal SCP20 cells recovered the metastasis ability to the level of SCP20 (Supplemental Fig. S3B).

\section{Overexpression of ADAMTS1 and MMP1 promotes bone metastasis}

To further validate the effect of ADAMTS1 and MMP1 in promoting osteolytic metastasis, a weakly metastatic clonal subline of MDA-MB-231, SCP6 (Fig. 1A), was engineered to overexpress these two genes either individually or in combination (Fig. 2A), and subjected to in vivo metastasis assays. Only the combined overexpression of both genes strongly promoted osteolytic bone metastases (Fig. 2B; Supplemental Fig. S4A). No effect on primary tumor growth was observed when one or both of the two genes were overexpressed (Supplemental Fig. S4B). To further prove that modulating the activity of ADAMTS1 and MMP1 could change the bone metastasis behavior of tumor cells, we used a mildly metastatic MDA-MB-231 
A

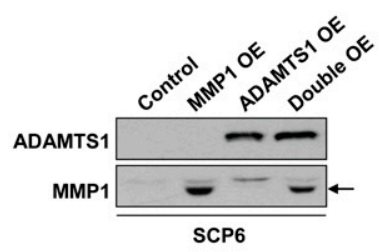

B

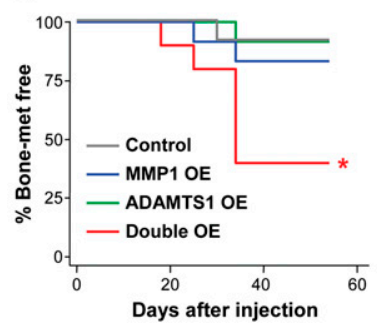

C

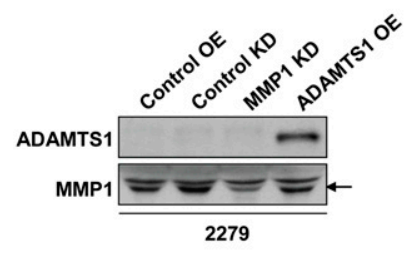

D

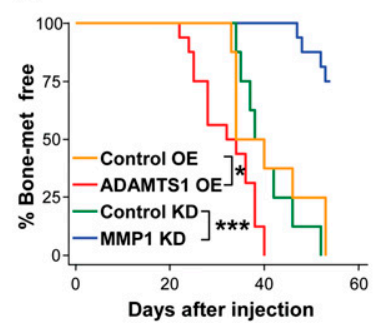

E

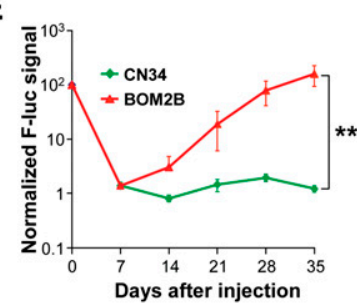

$\mathbf{F}$

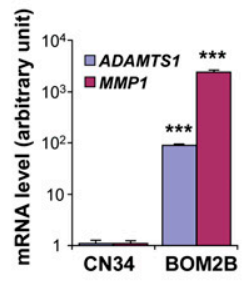

Figure 2. Overexpression of ADAMTS1 and MMP1 in weakly metastatic cells promotes bone metastasis. $(A)$ Low endogenous level and ectopic overexpression of ADAMTS1 and MMP1 in the weakly metastatic cell line SCP6 as confirmed by Western blot analysis of CM. (B) Kaplan-Meier curve showing the development of bone metastases in mice injected with different SCP6 sublines listed in $A$. $n=$ 10. $\left(^{*}\right) P<0.05$ based on log-rank test. $(C)$ Western blot analysis of ADAMTS1 and MMP1 in the CM of various sublines of 2279 that were engineered to knockdown MMP1 expression or ectopically express ADAMTS1. (D) Kaplan-Meier curve showing the development of bone metastases in different 2279 sublines. $n=10 .\left(^{\star}\right) P<0.05 ;\left(^{\star \star \star}\right) P<0.001$ based on log-rank test. $(E)$ CN34 and BOM2B were evaluated for the bone metastatic ability in mice, shown are normalized BLI signals in the hindlimb region. $(F)$ Expression of $A D A M T S$ and MMP1 assessed by qRT-PCR in the primary breast carcinoma cells CN34 and BOM2B. In $E$ and $F$ data represent average \pm SEM. $n=$ 10. $\left(^{\star \star}\right) P<0.01 ;\left(^{\star \star \star}\right) P<0.001$ based on two-sided Student's $t$-test.

subline, 2279, which overexpresses MMP1 but not ADAMTS1 (Fig. 1A). When MMP1 expression was silenced by shRNA (Fig. 2C), the cells showed reduced osteolytic metastasis activity (Fig. 2D; Supplemental Fig. S4C). Conversely, ADAMTS1 overexpression in 2279 increased metastasis ability significantly as compared with the vector control.

To extend the validation of the bone metastasis promoting function of MMP1 and ADAMTS1, we used MCF7 and MDA-MB-435, two breast cancer cell lines that are known to generate osteolytic bone metastasis (Rucci et al. 2004; Phadke et al. 2006). Even though MDAMB-435 was recently suspected to be of melanoma origin (Rae et al. 2007), it remains a good model to study the general gene functions in osteolytic bone metastasis. Consistent with our observation in MDA-MB-231 sublines, while single overexpression of either MMP1 or ADAMTS1 only modestly affected the bone metastasis potential, double overexpression significantly accelerated the formation of bone metastases by MCF7 and MDAMB-435 cell lines in nude mice (Supplemental Figs. S5, S6). Taken together, these data clearly indicate that ADAMTS1 and MMP1 act in concert to promote osteolytic bone metastasis in breast cancer, and that a combined targeting of both proteases is required to reduce the bone metastagenicity of the tumor cells.

The link between MMP1 and ADAMTS1 overexpression and bone metastasis was further supported by in vivo metastasis assays of primary breast tumor cells, CN34, isolated from the pleural effusion of a breast cancer patient treated at the Memorial Sloan-Kettering Cancer Center (MSKCC). A derivative cell population, BOM2B, was isolated after two rounds of in vivo selection from the bone metastasis formed by $\mathrm{CN} 34$ in nude mice. When reinjected into nude mice, BOM2B displayed significantly higher bone metastatic ability than the parental cells (Fig. 2E). When the expression of ADAMTS1 and MMP1 was assessed using quantitative RT-PCR (qRT-PCR), both genes were dramatically up-regulated in BOM2B (Fig. 2F).

The proteolytic activities of ADAMTS1 and MMP1 may contribute to colonization of tumor cells in the bone by promoting invasion and migration. In the transwell invasion assay, $A D A T M S 1$ and $M M P 1$ knockdown significantly reduced the invasive behaviors of the tumor cells through Matrigel or human bone marrow endothelial cell (HMBEC) barriers, particularly in the case of combined knockdown (Supplemental Fig. S7). However, the dramatic reduction of osteolytic bone metastasis ability of the double-knockdown cells could not be fully accounted for simply by the loss of invasiveness. The paucity of TRAP-positive osteoclasts in small bone lesions generated by double-knockdown cells (Fig. 1D,E) and the frequent regression of these nascent metastases (Supplemental Fig. 1C) suggest that the double-knockdown cells may be defective in sustaining crucial interactions with bone stromal cells that are important for the survival and proliferation of disseminated breast cancer cells in the bone microenvironment (Mundy 2002; Roodman 2004; Guise et al. 2005). 
Lu et al.

Secreted factors from ADAMTS1- and

$M M P 1$-overexpressing cancer cells alter the balance of RANKL and OPG production by osteoblasts

As ADAMTS1 and MMP1 expression was correlated with osteolytic activity and the number of osteoclasts in bone metastases, we investigated the role of these genes in tumor-stimulated osteoclast activation. Mouse primary bone marrow cells were treated with the conditioned media $(\mathrm{CM})$ from the control and knockdown sublines of SCP20 in an in vitro osteoclastogenesis assay, and TRAPpositive multinucleated mature osteoclasts were scored (Fig. 3A,B). Primary bone marrow cells that were cultured without CM from tumor cells had very few TRAPpositive cells. In contrast, the CM of the SCP20 cell line induced extensive differentiation of osteoclasts. However, the osteoclast-activating ability of the $\mathrm{CM}$ was significantly reduced when the expression of MMP1 and ADAMTS1 was suppressed either individually, or more significantly, in combination. To determine whether ADAMTS1 and MMP1 can influence osteoclast differentiation by altering the expression or release of RANKL and OPG in osteoblasts, we used the SCP20 CM to culture the murine osteoblast cell line MC3T3-E1 that had been induced to fully differentiate with $\mathrm{L}$-ascorbic acid and determined the level of RANKL and OPG released from osteoblasts by immunoblotting (Fig. 3C). Mature MC3T3-E1 cells secreted a low level of RANKL and relatively high level of OPG (RANKL/OPG ratio = $0.16)$. This pattern was reversed by CM from tumor cells (RANKL/OPG ratio $=2.27)$. However, when MC3T3-E1 was cultured with CM from ADAMTS1/MMP1 doubleknockdown cells, OPG became the dominant species again $($ RANKL/OPG ratio $=0.45)$. Soluble RANKL and OPG were clearly derived from MC3T3-E1 cells rather than tumor cells as they were absent in the tumor cell $\mathrm{CM}$ (data not shown), although we could not rule out the possibility that tumor cells may also be induced to secret RANKL or OPG in the bone microenvironment.

\section{ADAMTS1 and MMP1 release EGF-like ligands from breast cancer cells to repress OPG expression in osteoblasts}

There could be two possible mechanisms by which ADAMTS1 and MMP1 regulate RANKL and OPG production from osteoblasts. They may alter the abundance of RANKL and OPG by direct proteolytic processing of these two osteoblast-derived cytokines, or by targeting their tumor cell-derived paracrine regulatory factors. We ruled out the first possibility since direct treatment of MC3T3-E1 osteoblasts by activated MMP1 and ADAMTS1 proteases did not change the production of OPG or RANKL (Supplemental Fig. S8). To identify tumor-secreted cytokines that are under proteolytic regulation by MMP1 and ADAMTS1, we used a human cytokine antibody array (120 cytokine species included) to identify differentially represented cytokine(s) in the $\mathrm{CM}$ from control and the single- or double-knockdown SCP20 cells. Only one cytokine, Amphiregulin (AREG), was found to be consistently reduced in abundance in the single-knockdown and, more significantly, doubleknockdown sublines (Fig. 3D). AREG is a member of the EGF family cytokines. An antibody against EGF was also present in the array but did not reveal any detectable level of expression. Based on our previous microarray analysis
Figure 3. ADAMTS1 and MMP1 promote osteoclastogensis by shedding EGF-like growth factors from tumor cells. $(A, B)$ Induction of osteoclastogenesis in murine primary bone marrow cells by CM from various SCP20 sublines. Differentiated multinucleated osteoclasts were revealed by TRAP staining. Representative images of TRAP-staining are shown in $A$ and quantification of TRAP-positive cells is shown in $B$. Data represent average $\pm \mathrm{SD} .\left(^{*}\right)$ $\left.P<0.05 ;{ }^{\star \star \star}\right) P<0.001$ with two-sided Student's $t$-test. $(C)$ Alteration of RANKL/OPG abundance ratio in osteoblasts by ADAMTS1 and MMP1 to favor osteoclast differentiation. RANKL and OPG were detected with immunoblotting in the culture media of osteoblast MC3T3-E1 in different conditions. $(D)$ Identification of differentially expressed cytokines in the CM using a human cytokine antibody array. Signal intensities corresponding to each cytokine in the CM from knockdown cells were plotted against its intensity from the control cells. AREG was highlighted with a dotted circle to show its consistent down-regulation in MMP1 and/or ADAMTS1 knockdown cells. $(E)$ Western blot showing the level of three EGF-like factors, AREG, HB-EGF, and TGF $\alpha$, in the CM from SCP20 sublines. (F) Cleavage of the in vitro translated full-length EGF-like factors by recombinant MMP1. An Escherichia coli endogenous biotinylated protein served as loading control.

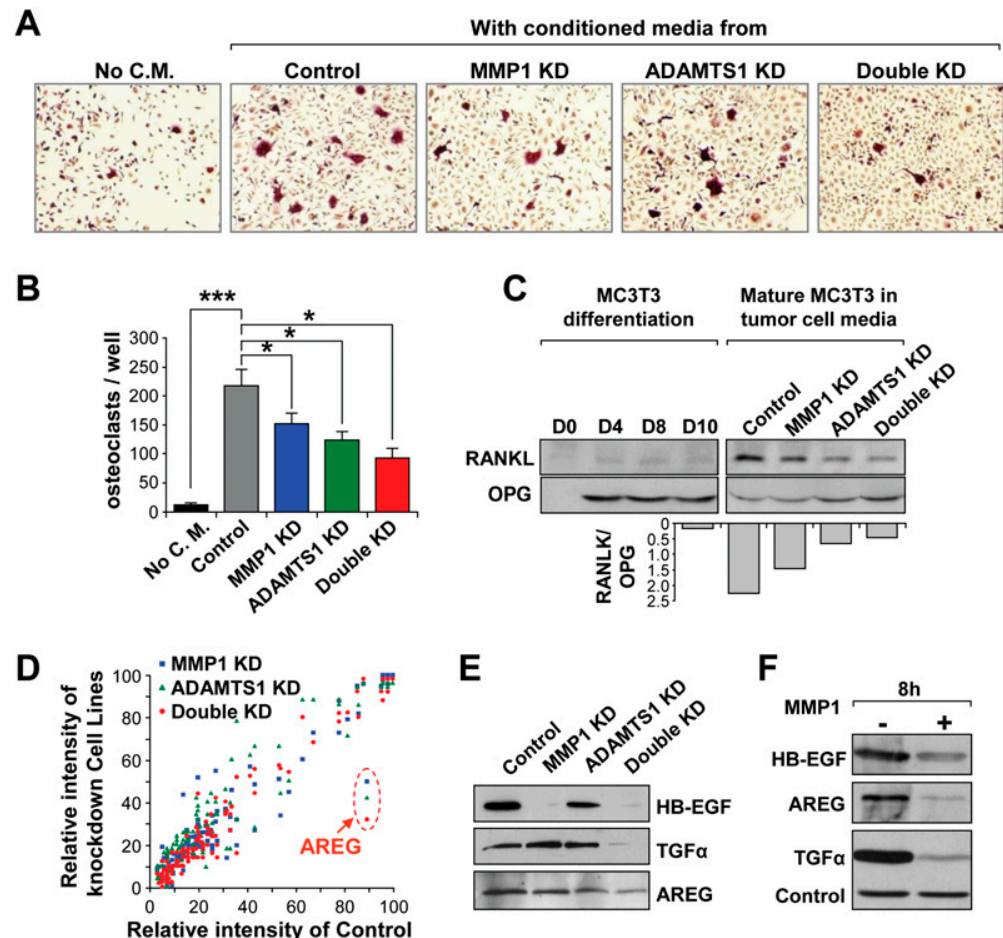


of SCP20 and other MDA-MB-231 variants (Kang et al. 2003), we used immunoblotting to analyze several additional EGF family members that are expressed in appreciable levels in these cells. Heparin-binding EGF (HBEGF) and transforming growth factor $\alpha$ (TGF $\alpha$ ) were also found to be significantly lower in the CM of single- and/or double-knockdown lines compared with the control line (Fig. 3E). The changes in the expression of these EGF-like ligands were not regulated at the mRNA level, as determined by Northern blot analysis (Supplemental Fig. S9). Taken together, these results suggest that the different abundance of these EGF-like growth factors in CM is controlled at the post-translational level.

Metalloproteinases have been known to participate in the shedding and maturation of membrane-bound growth factors (Page-McCaw et al. 2007). ADAMTS1 and MMP1 may increase the bioavailability of EGF family growth factors in the CM by mediating their shedding from the cell membrane. Recently, EGF-like ligands were shown to be released by ADAMTS1 (Liu et al. 2005). We tested if MMP1 could also proteolytically cleave EGF-like ligands by incubating in vitro translated and biotinynated AREG, HB-EGF, and TGF $\alpha$ with activated MMP1. The translated products were indeed specifically cleaved after incubation with MMP1 (Fig. 3F).

\section{EGF-like ligands reduce OPG expression in osteoblasts and potentiate osteoclastogenesis}

Having confirmed that AREG, HB-EGF, and TGF $\alpha$ bioavailability was regulated by ADAMTS1 and MMP1, we tested whether these tumor-derived EGF-like ligands could elicit a signaling cascade in osteoblasts to alter the expression of RANKL and OPG. This is biochemically possible as osteoblasts express functional EGFR, the receptor for AREG, HB-EGF, and TGF $\alpha$ (Normanno et al. 2005a; Zhu et al. 2007). In contrast, osteoclasts have been shown to lack the expression of EGFR (Tanaka et al. 1998). Soluble recombinant human AREG, HB-EGF, and TGF $\alpha$ were added individually or in combination into mature osteoblast cultures of two murine osteoblast cell lines, MC3T3-E1 and 7F2, and one human osteoblast cell line hFOB1.19. Immuonblotting and ELISA were used to measure RANKL and OPG levels in the CM (Fig. 4A,B). While RANKL level was unaffected (data not shown), OPG expression was significantly reduced by the EGFlike ligands, and the regulation was on the mRNA level (Supplemental Fig. S10). Down-regulation of OPG secretion from osteoblasts by EGF-like factors may potentiate osteoclast differentiation. Indeed, we observed treatment of three EGF-like factors, either individually or simultaneously, significantly increased the number of mature osteoclasts in the mouse bone marrow culture (Fig. 4C), and this increase could be ablated by EGFR-neutralizing antibody cetuximab or EGFR kinase inhibitor gefitinib (Fig. 4D). More importantly, these agents also suppress the ability of the tumor CM to potentiate osteoclastogenesis (Fig. 4E), suggesting that inhibiting EGFR signaling in the osteoblasts may reduce the osteoclastactivating ability of tumor cells.

\section{Targeting EGFR activity in the bone stroma blocks the development of bone metastasis}

Despite a high level of EGFR expression, MDA-MB-231 lacks proliferative response to EGF (Price et al. 1999) and is resistant to the growth arrest by the EGFR kinase inhibitor gefitinib in vitro (Davidson et al. 1987) and in vivo (Wakeling et al. 2002). Consistent with these previous observations, we found that in vitro proliferation of MDAMB-231 and its derivative SCP20 was unaffected by cetuximab or gefitinib at concentrations that significantly
A
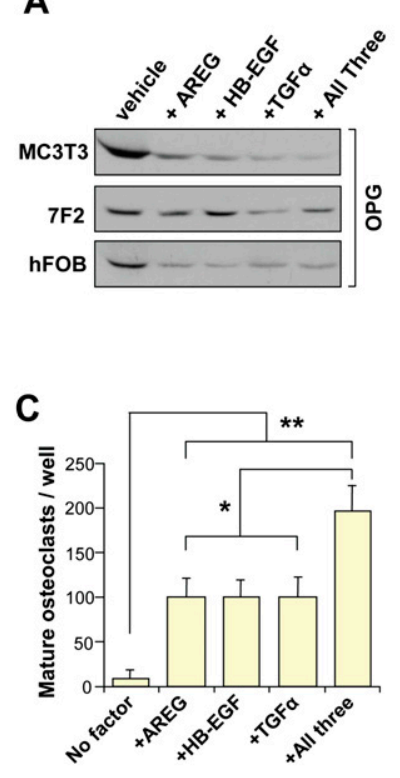

B
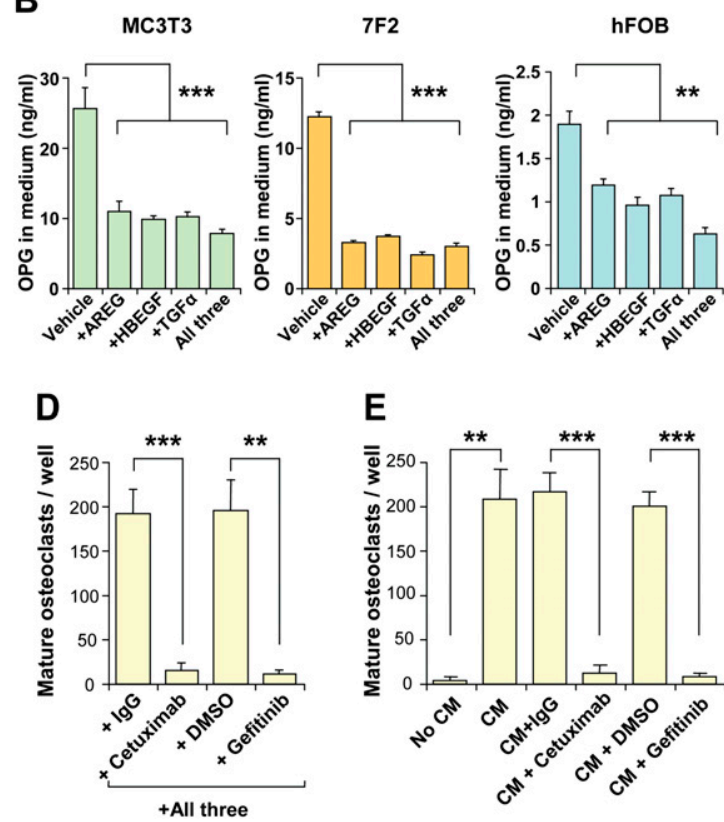

Figure 4. EGF-like growth factors inhibit OPG expression in osteoblasts and promote osteoclastogenesis. $(A, B)$ Inhibition of the OPG expression in murine osteoblasts MC3T3-E1 and 7F2 as well as human osteoblast hFOB treated with recombinant AREG, HB-EGF, and TGF $\alpha$ individually or in combination, measured by immunoblotting $(A)$ and ELISA $(B)$ of the CM. (C) EGF-like ligands increase osteoclastogenesis in murine primary bone marrow cells. (D) Inhibition of EGF-like ligand induced osteoclastogenesis by anti-EGFR antibody cetuximab or EGFR kinase inhibitor gefitinib. (E) Inhibition of SCP20 CM induced osteoclastogenesis by cetuximab or gefinitib. In $B-E$, data represent average $\pm \mathrm{SD} .\left(^{\star}\right) P<0.05 ;\left(^{\star \star}\right) P<0.01 ;\left(^{\star \star \star}\right) P<$ 0.001 with two-sided Student's $t$-test. 
Lu et al.

inhibit growth of various EGFR inhibitor-sensitive cell lines, including BT474 (breast cancer) and A549 (lung cancer) (Fig. 5A,B). When tested as xenograft mammary tumors, SCP20 failed to show response to cetuximab, gefitinib, or the combined treatment (Fig. 5C). However, when SCP20 was inoculated into nude mice by intracardiac injection to form bone metastasis, mice treated with either cetuximab and/or gefitinib showed dramatically lower bone metastasis burdens $(P<0.0001)$ (Fig. 5D-F). Overall, $100 \%$ of mice in the control group (treatment with drug vehicle only) developed osteolytic bone metastases, whereas only $30 \%$ of the mice from the groups treated with a single drug developed bone metastases (with significantly lower metastasis burdens). Combined treatment with both drugs completely abolished the formation of metastasis, suggesting a superior performance of the combinatorial regime over single agent targeting of EGFR. To further evaluate whether EGFR inhibitors suppress bone metastasis by blocking EGFR-dependent tumor-stroma interaction in the bone microenvironment or by blocking earlier steps of metastasis following intracardiac injection (i.e., survival in the circulation and extravasation), we inoculated SCP20 cells directly into the tibial metaphysis through intratibial injection and monitored the bone metastasis formation with or without EGFR inhibitor treatments. Similar to the results from the intracardiac injection experiment, mice treated with cetuximab or/and gefitinib did not develop any significant metastasis in tibia, whereas the control mice developed massive osteolytic metastases $(P<0.01)$ (Fig. $5 \mathrm{G}, \mathrm{H})$. Taken together, the results indicate that osteolytic bone metastasis can be successfully controlled by using clinically available EGFR inhibitors to target tumorstroma interaction in the bone microenvironment, even when tumor cells do not have anti-proliferative response to EGFR inhibitors.

\section{Elevated expression of MMP1 and ADAMTS1 in breast cancer increases risk of bone metastasis}

To investigate the prevalence of MMP1 and ADAMTS1 overexpression in breast cancer and their clinical relevance to bone metastasis, we first examined the frequency of MMP1 and ADAMTS1 overexpression in a breast cancer tissue array consisting of a total of 146 samples: four cases of stromal tissue, two cases of hyperplasia, five cases of ductal carcinoma in situ (DCIS), 100 cases of primary invasive ductal carcinoma, 18 cases of invasive lobular carcinoma, and 17 cases of poorly differentiated breast carcinoma. Immunohistochemical analysis of MMP1 and ADAMTS1 revealed that MMP1 was found to be expressed by both carcinoma cells and stromal cells in nearly all of the breast tumor samples (>98\%). However, the expression of ADAMTS1 was largely restricted to cancer cells in a subset of the breast carcinoma samples $(39.7 \%)$ and was not found to be expressed in stromal breast tissues or hyperplasia. Thus, MMP1 and ADAMTS1 were simultaneously expressed in a significant proportion of primary breast tumors (Fig. 6A).

MMP1 was previously reported to be a putative breast cancer predictive marker (Poola et al. 2005), yet its connection with tissue-specific metastasis of breast cancer
Figure 5. Targeting EGFR signaling activity in the bone stroma blocks the formation of bone metastasis. $(A, B)$ In vitro proliferation of MDA-MB-231 and its derivative SCP20 was unaffected by treatment with cetuximab or gefitinib. As a control, the proliferation of human breast cancer cell BT474 and lung carcinoma cell A549 was significantly inhibited by the drugs. Data represent average $\pm \mathrm{SD}$; $\left(^{\star}\right) P<0.05 ;\left(^{\star \star}\right) P<0.01$ with two-sided Student's $t$-test. $(C)$ Primary tumor growth of SCP20 was unaffected by treatment with cetuximab or/and gefitinib in vivo. (D) Single or combined treatment with cetuximab and gefitinib dramatically decreases the development of bone metastasis, as quantified by BLI analysis, after intracardiac injection of SCP20 cells. Data represent average $\pm \mathrm{SD}_{;}\left({ }^{\star \star \star}\right) P<0.001$ with Mann-Whitney test. $n=10$. (E) Reduction of the frequency of bone metastases formation in the mice treated with the drugs. $(F)$ Representative mice in the control and treatment cohorts with BLI and X-ray images taken at day 41. $(G)$ Treatment with cetuximab or/and gefitinib inhibits the formation of bone metastasis after intratibial injection of SCP20 cells, as quantified by BLI analysis. Data represent average \pm SEM with $n=5$ at day $\left.\left.45 \dot{r}^{\star \star}\right) P<0.01 ;\left.\right|^{\star \star \star}\right) P<0.001$ with Mann-Whitney test. $(H)$ Representative BLI images of hindlimbs of mice at day 45.
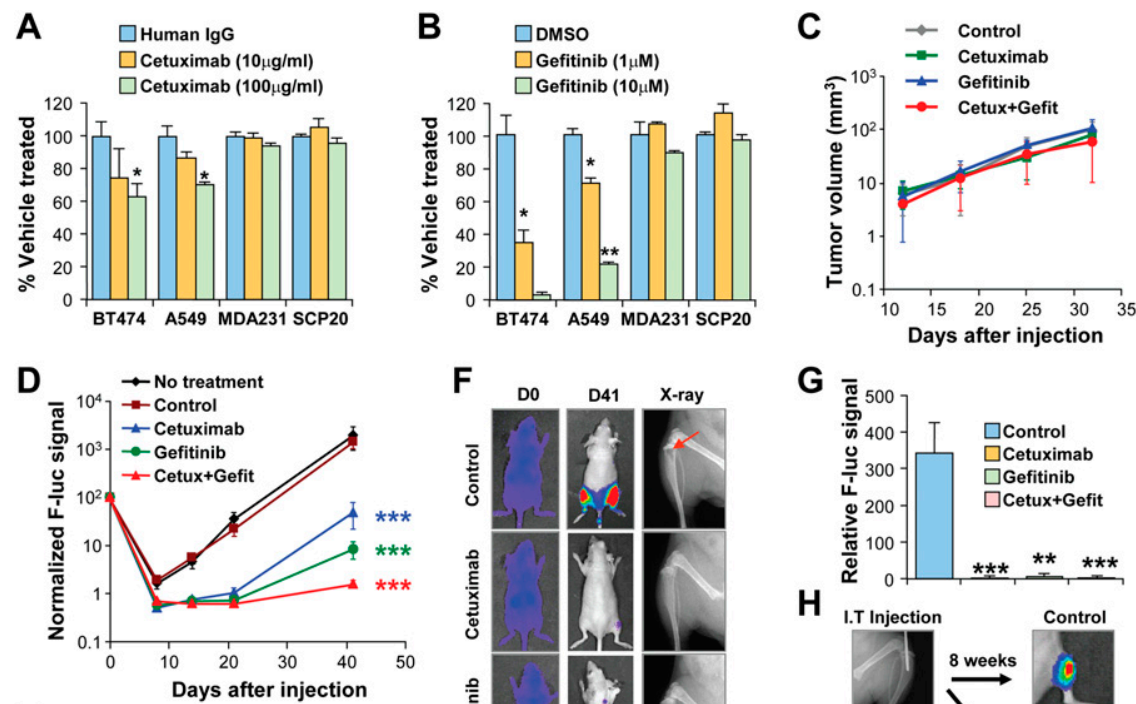

E

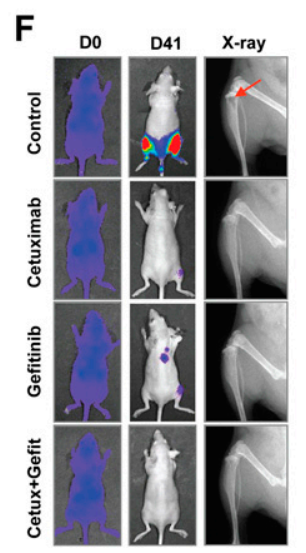

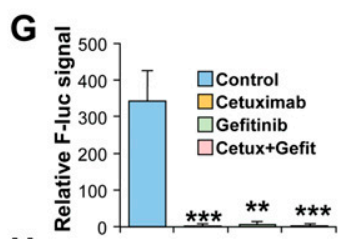

H

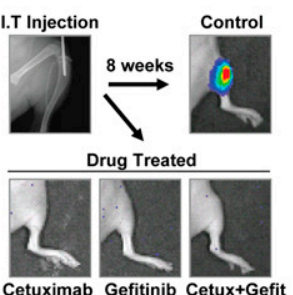


A
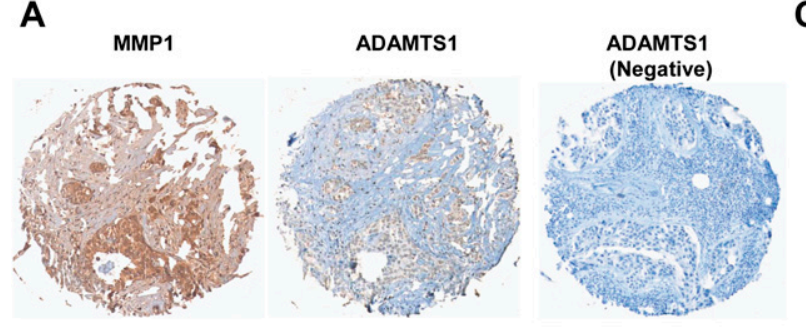

C

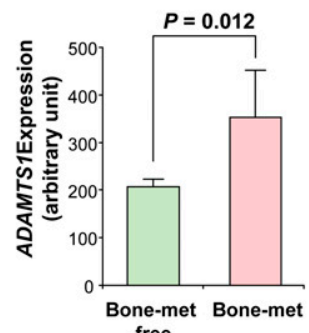

free

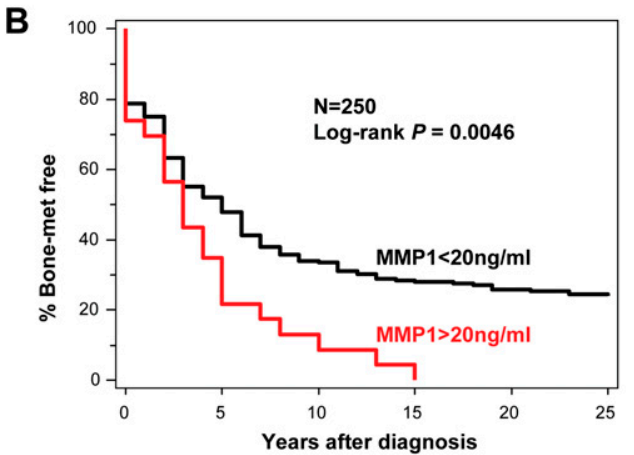

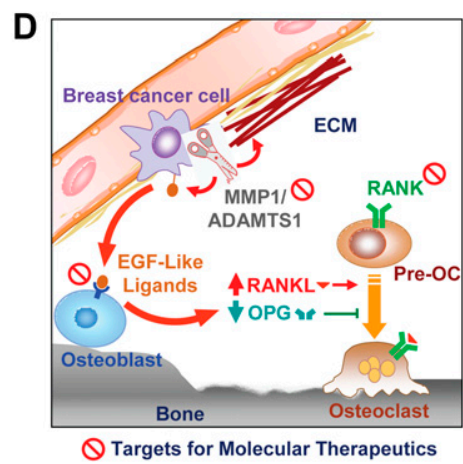

Figure 6. Expression and prognostic value of ADAMTS1 and MMP1 in human breast cancer and a model for their mechanism of action in promoting bone metastasis. (A) Immunohistochemical staining of ADAMTS1 and MMP1 on a tissue array of human breast cancer samples. Shown is a typical case of infiltrating ductal carcinoma with evident expression of both MMP1 and ADAMTS1 in the tumor cells (left and middle images), as well as a tumor sample with negative staining for ADAMTS1 (right image). (B) Kaplan-Meier curve showing that high level of MMP1 in the serum of breast cancer patients is correlated with a higher risk of bone metastasis. $(C)$ Expression level of ADAMTS1 in primary breast tumors with or without subsequent development of bone metastasis. Expression levels of ADAMTS1 were extracted from the microarray data in a previous study (Minn et al. 2005a). Data represent average $\pm \mathrm{SD}$ with $P$-value shown from two-sided Student's $t$-test. $(D)$ A schematic model for the function of ADAMTS1 and

MMP1 in bone metastasis of breast cancer. ADAMTS1 and MMP1 synergistically promote the invasion of breast cancer cells through the endothelium and the underlying connective tissue in the parenchyma of the metastasis site. The two metalloproteinases also shed EGF-like ligands, including HB-EGF, AREG, and TGF $\alpha$, from the surface of the tumor cells. These growth factors downregulate the expression of OPG in the osteoblasts. MMP1 and ADAMTS1 also increase the production of RANKL through an unknown mechanism. Increase of the RANKL-to-OPG ratio in the bone microenvironment promotes osteoclast differentiation and bone destruction.

has not been described. Since relevant bone metastasis information of the samples in the breast cancer tissue array was not available, we instead performed MMP1 ELISA on the serum samples from 250 breast cancer patients for whom clinical data of their bone metastasis status had been collected. A high level of serum MMP1 (>20 ng/mL) was significantly correlated with the presence of bone metastasis in breast cancer patients $(P=$ 0.0046) (Fig. 6B). We were unable to perform a similar analysis on serum ADAMTS1 as an effective ELISA assay for ADAMTS1 could not be established. Nevertheless, by using the microarray data from a previously published data set of 82 primary tumor samples obtained from breast cancer patients treated at the MSKCC (Minn et al. 2005a), ADAMTS1 mRNA was found to be expressed at a significantly higher level in the primary tumors from patients who developed bone metastasis (Fig. 6C). Together, these results validated overexpression of MMP1 and ADAMTS1 in a significant proportion of breast tumors and their association with higher risk of bone metastasis.

\section{Discussion}

Metalloproteinases, including MMP, ADAM, and ADAMTS family members, play important roles in development, tissue remodeling, and cancer progression (Egeblad and Werb 2002; Mochizuki and Okada 2007; Page-McCaw et al. 2007). Their perceived functions in metastasis have been associated mainly with their ability to col- lectively degrade all components of the ECM, thereby promoting tumor cell migration and invasion. In recent years, it has become increasingly clear that the substrates for metalloproteinase also include many nonmatrix extracellular and membrane-bound proteins, including protease precursors and inhibitors, cytokines, latent growth factors, growth factor-binding proteins, and adhesion molecules (McCawley and Matrisian 2001). Understanding how metalloproteinases promote organspecific metastasis through altering the signaling milieu in the tumor-stroma microenvironment is crucial for developing better molecular therapeutics for metastatic cancer.

The involvement of MMPs and related metalloproteinases in bone metastasis has long been speculated based on the bone remodeling defect of MMP-deficient animals (Page-McCaw et al. 2007), the production of MMPs by osteoclasts during bone resorption (Reponen et al. 1994; Tezuka et al. 1994), the ability of MMPs to degrade major components of bone matrix (Bonfil et al. 2004), the high level of MMP expression in tumors, and their correlations with poor clinical outcomes (Coussens et al. 2002). Broadspectrum MMP inhibitors have been tested in preclinical models of bone metastasis and proven to be effective in reducing bone destruction. For example, tissue inhibitor of metalloproteinase-2 (TIMP-2) and broad-spectrum MMP inhibitors, including Batimastat (BB-94), GM 6001, and Neovastat (AE-941), were found to significantly reduce bone metastasis of the MDA-MB-231 breast cancer cells in vivo (Yoneda et al. 1997; Lee et al. 2001; 
Nemeth et al. 2002; Weber et al. 2002; Winding et al. 2002). However, the specific involvement and functional mechanisms of individual metalloproteinase in bone metastasis remain poorly characterized. In this study, we show that MMP1 and ADAMTS1 act in concert to not only enhance invasion through the ECM and endothelium, but also to promote tumor colonization in the bone microenvironment through an intricate pro-osteolytic signaling cascade that involves tumor cells, osteoblasts, and osteoclasts (Fig. 6D). MMP1 and ADAMTS1 proteolytically release EGF-like ligands, including AREG, HB-EGF, and TGF $\alpha$, from tumor cells. These EGF family growth factors signal through the EGFR pathway in osteoblasts to inhibit the expression of OPG. MMP1 and ADAMTS1 also increase the release of RANKL by osteoblasts through an unknown mechanism, as RANKL secretion from cultured osteoblasts was not altered by direct treatment of either the two proteases or the EGF-like growth factors. Overall, ADAMTS1/MMP1 overexpression in tumor cells significantly increased the production ratio of RANKL to OPG by osteoblasts, tipping the balance toward osteoclast activation (Fig. 6D).

In this osteolytic paracine scheme, the central role of EGF-like growth factor signaling in osteoblast suggested a potential therapeutic window for applying EGFR inhibitors in the treatment of bone metastasis. The oncogenic function of the EGF family growth factors and their receptors has been extensively validated in experimental and clinical settings (Hynes and Lane 2005). The involvement of the EGFR signaling pathway in bone metastasis is less well characterized but has been implicated by a number of studies. For example, EGFR deficiency in mice results in delayed primary endochondral ossification because of impaired recruitment and formation of osteoclasts (Wang et al. 2004). Conversely, EGF transgenic mice show postnatal growth retardation as a result of abnormal bone turnover (Chan and Wong 2000). EGF and TGF $\alpha$ can strongly stimulate bone resorption in vitro (Ibbotson et al. 1986; Lorenzo et al. 1986; Takahashi et al. 1986), and EGFR signaling has been shown to affect the expression of OPG and monocyte chemoattractant protein-1 in osteoblast cells and promote osteoclast differentiation in vitro (Zhu et al. 2007). Intriguingly, although EGFR inhibitors have been proven to have little activity in breast cancer patients as single agents (Normanno et al. 2005b), dramatic reduction of bone pain has been documented in phase II clinical trials of EGFR inhibitors in breast cancer patients with bone metastasis (Albain et al. 2002; von Minckwitz et al. 2003). Our study linked the proteolytic shedding of EGF-like growth factors to an EGFR-dependent paracrine proosteolysis signaling cascade, and provided a molecular basis to place EGF family ligands in the vicious cycle of bone metastasis (Fig. 6D). Importantly, the osteolytic signaling pathway revealed in our current study depends on the EGFR signaling pathway in osteoblasts, suggesting that EGFR inhibitors may be effective for treatment of bone metastasis, even for patients whose primary tumors are nonresponsive to EGFR inhibitors. Indeed, we ob- served that EGFR inhibitors can effectively suppress the development of bone metastasis by an EGFR inhibitornonsensitive breast cancer cell line, MDA-MB-231 (Fig. 5). Further functional characterization of the EGF family ligands in preclinical models of bone metastasis will provide additional rationale for clinical trials of EGFR inhibitors in bone metastasis.

In conclusion, our study revealed the functional importance of MMP1 and ADAMTS1 as well as stromal EGFR signaling in bone metastasis. Elevated levels of both MMP1 and ADAMTS1 were detected in nearly 40\% of breast cancers. This observation, together with the prevalence of TGF $\alpha$, AREG, and HB-EGF in breast tumors (37\%-80\%) (Normanno et al. 2005b), suggest that molecular targeting of MMP1 and ADAMTS1, combined with inhibition of EGFR, may potentially reduce the risk of bone metastasis for a significant number of breast cancer patients. Furthermore, a high level of serum MMP1 strongly correlates with higher risk of bone metastasis and may serve as a predictive marker for the application of MMP or EGFR inhibitors in the treatment of bone metastasis.

\section{Materials and methods}

\section{Cell culture}

The SCP20, SCP6, and 2279 sublines were derived from the parental cell line MDA-MB-231 (American Type Culture Collection [ATCC]) (Kang et al. 2003). These sublines and their genetically modified variants were maintained in DMEM supplemented with $10 \%$ FBS, antibiotics, and appropriate selection drugs for transfected plasmids. H29 cells, a packaging cell line for retrovirus production, were maintained in DMEM supplemented with $10 \%$ FBS, $2 \mathrm{mM}$ glutamine, and antibiotics. MCF7 and MDA-MB-435 were purchased from ATCC and cultured following ATCC's instructions. The human bone marrow endothelial cells line HBMEC-60, generously provided by Dr. C. Ellen van der Schoot (University of Amsterdam, Amsterdam, The Netherlands), was maintained in Basal Medium 200 (Cascade Biologicals) supplemented with $20 \%$ FBS, $1 \mu \mathrm{g} / \mathrm{mL}$ hydrocortisone, 3 $\mathrm{ng} / \mathrm{mL}$ human fibroblast growth factor, $10 \mu \mathrm{g} / \mathrm{mL}$ heparin, and 10 $\mathrm{ng} / \mathrm{mL}$ human epidermal growth factor (Rood et al. 2000; Glinsky et al. 2001). Human umbilical vein endothelial cells (HUVEC) (Lonza) were maintained in the EBM-2 basal medium supplemented with the EGM-2 SingleQuot growth factors (Lonza). The murine cell line MC3T3-E1 subclone 4 (ATCC) was maintained as preosteoblasts in growth medium $\alpha$-MEM supplemented with $10 \%$ FBS and antibiotics. When switched to the differentiation condition (growth medium supplemented with $50 \mu \mathrm{g} / \mathrm{mL}$ L-ascorbic acid) with medium changed every $2 \mathrm{~d}$, the cells differentiated into mature osteoblasts in $7 \mathrm{~d}$ as evidenced by von Kossa staining. The murine osteoblast cell line 7F2 (ATCC) was cultured in $\alpha$-MEM with $10 \%$ FBS (Thompson et al. 1998). The human cell line hFOB1.19 (ATCC) was maintained as preosteoblasts in DMEM:F12 without phenol red supplemented with $0.3 \mathrm{mg} / \mathrm{mL}$ G418 and $10 \%$ FBS at $34^{\circ} \mathrm{C}$. When switched to $39.5^{\circ} \mathrm{C}$ for $2 \mathrm{~d}$ after confluence, the cells differentiated into mature osteoblasts and the medium was collected (Harris et al. 1995). BT474 cells were maintained in RPMI1640 with $10 \%$ FBS, $10 \mu \mathrm{g} / \mathrm{mL}$ bovine insulin, and antibiotics. A549 cells were maintained in DMEM with 10\% FBS and antibiotics. 
Generation of knockdown, overexpression, and expression-rescued cells

Stable shRNA-mediated knockdown was achieved with the pSuper-Retro system (with puromycin or hydromycin as selection markers) (OligoEngine) targeting the following sequences: 5'-GGGTCCCAGACATGTGATA-3' for ADAMTS1 and 5'-AGC GGAGAAATAGTGGCCC-3' for $M M P 1$. shRNA retroviral vectors were transfected into the packaging cell line H29. After $48 \mathrm{~h}$ viruses were collected, filtered, and used to infect target cells in the presence of $5 \mu \mathrm{g} / \mathrm{mL}$ polybrene. The infected cells were selected with $0.5 \mu \mathrm{g} / \mathrm{mL}$ puromycin. ADAMTS1 and MMP1 overexpression were achieved using the retroviral expression vector pMSCVneo and pMSCVhyg, respectively. Viruses were generated and used to infect target cells as above and the infected cells were selected with $1.0 \mathrm{mg} / \mathrm{mL}$ G418 or $0.4 \mathrm{mg} / \mathrm{mL}$ hygromycin. ADAMTS1 rescue was obtained by creating four silent point mutations in the shRNA targeted sequence $15^{\prime}$-GGGAGC CAAACGTGTGATA-3') in the ADAMTS1-pMSCVneo overexpression plasmid. MMP1 was rescued in the similar way (5'AGCGGAGGAACTCTGGCCC-3'). In order to avoid clonal variations, a pooled population of at least 500 independent clones of each transfection/transduction was used to generate each stable cell line used in this study

\section{Tumor xenografts and analysis}

All procedures involving mice, such as housing and care, and all experimental protocols were approved by Institutional Animal Care and Use Committee (IACUC) of Princeton University. For intracardiac injections, cells were harvested from subconfluent cell culture plates, washed with PBS twice, and resuspended at $1 \times 10^{6}$ per milliliter in PBS. Suspended cells $(0.1 \mathrm{~mL})$ were injected into the left cardiac ventricle of 4-wk-old, female nude mice (NCI) using 26-gauge needles as described previously (Arguello et al. 1992). Mice were anesthesized with ketamine (100 mg/kg body weight) and xylazine (10 mg/kg body weight) before injection. For intratibial injection, 30-gauge needles were used to inject $1 \times 10^{5}$ cells in $10 \mu \mathrm{L}$ into the tibia in anesthetized mice following the method described previously (Bakewell et al. 2003). Development of metastases in bone and other organs was monitored by BLI. Anesthetized mice were retroorbitally injected with 75 mg/kg D-Luciferin (6900-XR-1001, Caliper LifeScience). Bioluminescence images were acquired with the IVIS Imaging System (Xenogen). Analysis was performed with Living Image software (Xenogen) by measuring photon flux of the whole mouse body or a region of interest. Data were normalized to the signal obtained immediately after injection (day 0). X-ray radiography analysis of bone lesions was performed using procedures as described previously (Kang et al. 2003). For the orthotopic xenograft model, mammary fat pad injections and tumor size measurement were performed following the procedure described previously (Minn et al. 2005a). Caliper measurements of tumor mammary tumors were used to quantify tumor growth, as strong BLI signals quickly become saturated by the rapid growth of primary tumors.

\section{Histological analysis}

Hindlimb bones were excised, fixed in 10\% neutral-buffered formalin, decalcified, and embedded in paraffin for H\&E and TRAP staining (Kos et al. 2003). Osteoclast number was assessed as multinucleated TRAP-positive cells along the tumor-bone interface on TRAP-stained sections and expressed as osteoclast number per millimeter of interface (Yin et al. 2003).

\section{Human cytokine array}

CM from 24-h incubation of confluent cells was applied to the Human Cytokine Antibody Array C Series 1000 (Raybiotech) following the manufacturer's instruction.

\section{Osteoclastogenesis assay in vitro}

Bone marrow cells were flushed out from femora and tibiae from 6-wk-old FVB/N mice and plated in basal culture medium ( $\alpha$-MEM supplemented with $10 \%$ FBS, 2 mM L-Glutamine, and antibiotics) overnight. The next day, the nonadherent cells were plated at $1 \times 10^{6}$ per well in 24-well plates in a 1:1 mixture of basal culture medium/filtered CM (harvested from 24-h incubation of confluent tumor cells) supplemented with recombinant murine sRANKL (50 ng/mL) and recombinant murine MCSF (50 $\mathrm{ng} / \mathrm{mL}$ ). Alternatively, the cells were cultured in the supplemented basal medium added with recombinant human EGF-like factors at $10 \mathrm{nM}$. Medium was changed every $3 \mathrm{~d}$. TRAP staining was performed on day 6 using a leukocyte acid phosphotase kit from Sigma (Mitchell et al. 1996). TRAP-positive multinucleated cells were counted as mature osteoclasts and reported as the number of osteoclasts/well.

\section{Tissue array immunohistochemistry}

A breast cancer tissue microarray composed of 146 primary tumors was used to stain for ADAMTS1 and MMP1 expression. Tumor specimens were obtained from the Cancer Institute of New Jersey with informed consent from all subjects in accordance with the Institutional Review Boards of Princeton University and the University of Medicine and Dentistry of New Jersey. Immunohistochemistry was performed by the Tissue Analytic Core Facility in the Cancer Institute of New Jersey. Anti-human ADAMTS1 (a gift from Richard Leduc) and anti-human MMP1 (Chemicon) were first optimized on regular human breast tissue slides using Discovery XT automated immunostainer (Ventana Medical Systems). Breast cancer tissue array slides were deparaffinized and antigen retrieval was performed using either CC1 (Cell Conditioning Solution, Ventana Medical Systems) with extended time of $72 \mathrm{~min}$ for ADAMTS1 detection or protease I (Ventana Medical Systems) for MMP1 detection. ADAMTS1 and MMP1 antibodies were applied at the dilution of 1:10 and 1:50, respectively, and incubated at room temperature for $2 \mathrm{~h}$. Universal secondary antibody (Ventana Medical Systems) was applied for 12 min followed by chromogenic detection kit DABMap (Ventana Medical Systems). Slides were counterstained with hematoxylin and dehydrated with xylene.

Each tumor was represented on the arrays by four cores. Each core was scored as negative (0), low (1), medium (2), or high (3) according to staining intensities. The core scores from the same tumor were averaged to produce a single score. A tumor with an average score $>1$ was considered as positive for the expression of the gene.

\section{Serum samples and ELISA analysis of serum MMP1}

The serum samples used in the study came from breast cancer patients who have had serum stored at $-70^{\circ} \mathrm{C}$ within the MSKCC Clincal Chemistry repository. The Clinical Chemistry serum repository includes samples from patients who had serial assessment of CA-15.3 (or BR2729) and CEA over the past $7 \mathrm{yr}$ for clinical indications. In the adjuvant setting, these blood samples are drawn every 3-12 mo as part of MSKCC adjuvant care. In patients with metastatic disease, samples are routinely drawn monthly during follow up visits. Two-hundred-fifty serum 
specimens were selected from patients with or without evidence of metastases. A database with the clinicopathologic data of interest, including age, tumor characteristics (TNM, ER/PR/ HER2 status), involvement of metastasis, and conditions that may affect bone, as well as treatments administered, were constructed. Following the retrieval of samples, all patient identifiers were removed from the specimens to assure patient confidentiality. The identification, data collection, and material transfer were performed under a Waiver of Authorization that was reviewed and approved by the MSKCC Institutional Review Board and Princeton University Institutional Review Panel.

Serum MMP1 levels were assayed using a quantitative ELISA kit (Oncogene, catalog no. QIA55). The personnel performing the assay were blinded with regard to the patients' clinical status.

\section{Pharmacological inhibitors}

Cetuximab (Imclone) was obtained from the MSKCC pharmacy. Gefitinib (Iressa) was obtained from LC Laboratories. For in vitro proliferation assay, cells were seeded at $2 \times 10^{4}$ per well in 24 well plates. Twenty-four hours later, the cells were treated with control human IgG or cetuximab (10 and $100 \mu \mathrm{g} / \mathrm{mL})$, and DMSO or gefitinib (1 and $10 \mu \mathrm{M})$, respectively, for $5 \mathrm{~d}$ before the cell number was measured by counting with trypan blue as the viability dye. For osteoclastogenesis assay, cetuximab $(50 \mu \mathrm{g} / \mathrm{mL})$ or gefitinib $(5 \mu \mathrm{M})$ were added and renewed simultaneously with EGF-like factors or tumor cell CM. For xenograft experiments, mice were pretreated with the agents $1 \mathrm{~d}$ before tumor cell inoculation and subsequently treated in the following regime: (1) control: $0.05 \%$ Tween 80 vehicle by oral gavage daily and $1 \mathrm{mg}$ per mouse nonspecific purified human IgG in sterile PBS by i.p. injection twice a week; (2) gefitinib in $0.05 \%$ Tween 80 administered at $100 \mathrm{mg} / \mathrm{kg}$ per day and human IgG twice a week; (3) 1 mg per mouse cetuximab twice a week and $0.05 \%$ Tween 80 ; and (4) gefitinib and cetuximab using the doses as described in 2 and 3 (Moulder et al. 2001; Gupta et al. 2007).

\section{Statistical analysis}

Results were reported as mean \pm SD (standard deviation) or mean \pm SEM (standard error of the mean), indicated in the figure legend. Comparisons between Kaplan-Meier curves were performed using the log-rank test. Other comparisons were performed using unpaired two-sided Student's $t$-test without equal variance assumption or nonparametric Mann-Whitney test.

Additional experimental procedures, including invasion and transendothelial assays, Northern blot, and Western blot analysis, osteoblast assay, in vitro translation and proteolytic assay, qRT-PCR, in vivo selection, and characterization of bone-tropic CN34 variants are listed in the Supplemental Material.

\section{Acknowledgments}

We thank L. Qin, Y. Wei, N. Sethi, and members of our laboratories for helpful discussions; C. DeCoste for assistance with flow cytometry; M. Bisher for assistance with histology; M.A. Blanco for comments of the manuscript; J. Yan, M. Yuan, and C. Yan for technical assistance; A.B. Olshen for statistical advice; T.A. Guise and K.S. Mohammad for training and technical advice in bone histology; R. Leduc for ADAMTS1 antibodies; C.E. van der Schoot for HMBEC-60 cell line; O. Matveeva for shRNA oligo designs; and L. Cong, J. Friedman, and L. Goodell at Tissue Analytic Service Core of Cancer Institute of New Jersey for assistance with immunohistochemistry analysis of tissue arrays. Y.K. is a Champalimaud Investigator and a Department of Defense Era of Hope Scholar Award recipient. This research was additionally supported by grants from the American Cancer Society, the Susan G. Komen for the Cure, and the New Jersey Commission on Cancer Research. J.M. is an Investigator of the Howard Hughes Medical Institute and is funded by grants from the National Institutes of Health, the Kleberg Foundation, the Hearst Foundation, and the BBVA Foundation. X.L. is a recipient of a Harold W. Dodds Fellowship from Princeton University.

\section{References}

Albain K, Elledge R, Gradishar WJ, Hayes DF, Rowinsky E, Hudis C, Pusztai L, Tripathy D, Modi S, Rubi S. 2002. Openlabel, phase II, multicenter trial of ZD1839 ('Iressa') in patients with advanced breast cancer. Breast Cancer Res Treat 76: S33 (Abstract 20). doi: 10.1023/A:1021560101414.

Arguello F, Furlanetto RW, Baggs RB, Graves BT, Harwell SE, Cohen HJ, Frantz CN. 1992. Incidence and distribution of experimental metastases in mutant mice with defective organ microenvironments (genotypes $\mathrm{Sl} / \mathrm{Sld}$ and $\mathrm{W} / \mathrm{Wv}$ ). Cancer Res 52: 2304-2309.

Bakewell SJ, Nestor P, Prasad S, Tomasson MH, Dowland N, Mehrotra M, Scarborough R, Kanter J, Abe K, Phillips D, et al. 2003. Platelet and osteoclast $\beta 3$ integrins are critical for bone metastasis. Proc Natl Acad Sci 100: 14205-14210.

Boire A, Covic L, Agarwal A, Jacques S, Sherifi S, Kuliopulos A. 2005. PAR1 is a matrix metalloprotease-1 receptor that promotes invasion and tumorigenesis of breast cancer cells. Cell 120: 303-313.

Bonfil RD, Osenkowski P, Fridman R, Cher ML. 2004. Matrix metalloproteinaes and bone metastasis. Cancer Treat Res 118: $173-195$.

Brinckerhoff CE, Rutter JL, Benbow U. 2000. Interstitial collagenases as markers of tumor progression. Clin Cancer Res 6: 4823-4830.

Chan S-Y, Wong RW-C. 2000. Expression of epidermal growth factor in transgenic mice causes growth retardation. I Biol Chem 275: 38693-38698.

Cheng S, Tada M, Hida Y, Asano T, Kuramae T, Takemoto N, Hamada J, Miyamoto M, Hirano S, Kondo S, et al. 2008. High MMP-1 mRNA expression is a risk factor for disease-free and overall survivals in patients with invasive breast carcinoma. J Surg Res 146: 104-109.

Coussens LM, Fingleton B, Matrisian LM. 2002. Matrix metalloproteinase inhibitors and cancer: Trials and tribulations. Science 295: 2387-2392.

Davidson NE, Gelmann EP, Lippman ME, Dickson RB. 1987. Epidermal growth factor receptor gene expression in estrogen receptor-positive and negative human breast cancer cell lines. Methods Enzymol 1: 216-223.

Egeblad, M. and Werb, Z. 2002. New functions for the matrix metalloproteinases in cancer progression. Nature Reviews 2: $161-174$

Glinsky VV, Glinsky GV, Rittenhouse-Olson K, Huflejt ME, Glinskii OV, Deutscher SL, Quinn TP. 2001. The role of Thomsen-Friedenreich antigen in adhesion of human breast and prostate cancer cells to the endothelium. Cancer Res 61: 4851-4857.

Guise TA, Kozlow WM, Heras-Herzig A, Padalecki SS, Yin JJ, Chirgwin JM. 2005. Molecular mechanisms of breast cancer metastases to bone. Clin Breast Cancer 5: S46-S53.

Gupta GP, Massague J. 2006. Cancer metastasis: Building a framework. Cell 127: 679-695.

Gupta GP, Nguyen DX, Chiang AC, Bos PD, Kim JY, Nadal C, Gomis RR, Manova-Todorova K, Massague J. 2007. Mediators of vascular remodelling co-opted for sequential steps in lung metastasis. Nature 446: 765-770. 
Harris SA, Enger RJ, Riggs BL, Spelsberg TC. 1995. Development and characterization of a conditionally immortalized human fetal osteoblastic cell line. J Bone Miner Res 10: 178-186.

Hynes NE and Lane HA. 2005. ERBB receptors and cancer: The complexity of targeted inhibitors. Nature Reviews 5: 341354.

Ibbotson KJ, Harrod J, Gowen M, D'Souza S, Smith DD, Winkler ME, Derynck R, Mundy GR. 1986. Human recombinant transforming growth factor $\alpha$ stimulates bone resorption and inhibits formation in vitro. Proc Natl Acad Sci 83: 22282232.

Kang Y, Siegel PM, Shu W, Drobnjak M, Kakonen SM, CordonCardo C, Guise TA, Massague J. 2003. A multigenic program mediating breast cancer metastasis to bone. Cancer Cell 3: 537-549.

Kos $\mathrm{CH}$, Karaplis AC, Peng JB, Hediger MA, Goltzman D, Mohammad KS, Guise TA, Pollak MR. 2003. The calciumsensing receptor is required for normal calcium homeostasis independent of parathyroid hormone. I Clin Invest 111: 1021-1028.

Kuno K, Kanada N, Nakashima E, Fujiki F, Ichimura F, Matsushima K. 1997. Molecular cloning of a gene encoding a new type of metalloproteinase-disintegrin family protein with thrombospondin motifs as an inflammation associated gene. I Biol Chem 272: 556-562.

Lee J, Weber M, Mejia S, Bone E, Watson P, Orr W. 2001. A matrix metalloproteinase inhibitor, batimastat, retards the development of osteolytic bone metastases by MDA-MB-231 human breast cancer cells in Balb $\mathrm{C}$ nu/nu mice. Eur $J$ Cancer 37: 106-113.

Liu Y-j, Xu Y, Yu Q. 2005. Full-length ADAMTS-1 and the ADAMTS-1 fragments display pro- and antimetastatic activity, respectively. Oncogene 25: 2452-2467.

Lorenzo JA, Quinton J, Sousa S, Raisz LG. 1986. Effects of DNA and prostaglandin synthesis inhibitors on the stimulation of bone resorption by epidermal growth factor in fetal rat longbone cultures. I Clin Invest 77: 1897-1902.

McCawley LJ, Matrisian LM. 2001. Matrix metalloproteinases: They're not just for matrix anymore! Curr Opin Cell Biol 13: 534-540.

Minn AJ, Gupta GP, Siegel PM, Bos PD, Shu W, Giri DD, Viale A, Olshen AB, Gerald WL, Massague J. 2005a. Genes that mediate breast cancer metastasis to lung. Nature 436: 518524.

Minn AJ, Kang Y, Serganova I, Gupta GP, Giri DD, Doubrovin M, Ponomarev V, Gerald WL, Blasberg R, Massague J. 2005b. Distinct organ-specific metastatic potential of individual breast cancer cells and primary tumors. J Clin Invest 115: 4455.

Mitchell PG, Magna HA, Reeves LM, Lopresti-Morrow LL, Yocum SA, Rosner PJ, Geoghegan KF, Hambor JE. 1996. Cloning, expression, and type II collagenolytic activity of matrix metalloproteinase-13 from human osteoarthritic cartilage. J Clin Invest 97: 761-768.

Mochizuki S, Okada Y. 2007. ADAMs in cancer cell proliferation and progression. Cancer Sci 98: 621-628.

Moulder SL, Yakes FM, Muthuswamy SK, Bianco R, Simpson JF, Arteaga CL. 2001. Epidermal growth factor receptor (HER1) tyrosine kinase inhibitor ZD1839 (Iressa) inhibits HER2/neu (erbB2)-overexpressing breast cancer cells in vitro and in vivo. Cancer Res 61: 8887-8895.

Mundy, G.R. 2002. Metastasis to bone: Causes, consequences and therapeutic opportunities. Nature Reviews 2: 584-593.

Nemeth JA, Yousif R, Herzog M, Che M, Upadhyay J, Shekarriz B, Bhagat S, Mullins C, Fridman R, Cher ML. 2002. Matrix metalloproteinase activity, bone matrix turnover, and tumor cell proliferation in prostate cancer bone metastasis. I Natl Cancer Inst 94: 17-25.

Normanno N, De Luca A, Aldinucci D, Maiello MR, Mancino M, D'Antonio A, De Filippi R, Pinto A. 2005a. Gefitinib inhibits the ability of human bone marrow stromal cells to induce osteoclast differentiation: Implications for the pathogenesis and treatment of bone metastasis. Endocr Relat Cancer 12: 471-482.

Normanno N, De Luca A, Maiello MR, Mancino M, D'Antonio A, Macaluso M, Caponigro F, Giordano A. 2005b. Epidermal growth factor receptor (EGFR) tyrosine kinase inhibitors in breast cancer: Current status and future development. Front Biosci 10: 2611-2617.

Overall CM, Lopez-Otin C. 2002. Strategies for MMP inhibition in cancer: Innovations for the post-trial era. Nat Rev Cancer 2: 657-672.

Page-McCaw A, Ewald AJ, Werb Z. 2007. Matrix metalloproteinases and the regulation of tissue remodelling. Nat Rev Mol Cell Biol 8: 221-233.

Phadke PA, Mercer RR, Harms JF, Jia Y, Frost AR, Jewell JL, Bussard KM, Nelson S, Moore C, Kappes JC, et al. 2006. Kinetics of metastatic breast cancer cell trafficking in bone. Clin Cancer Res 12: 1431-1440.

Poola I, DeWitty RL, Marshalleck JJ, Bhatnagar R, Abraham J, Leffall LD. 2005. Identification of MMP-1 as a putative breast cancer predictive marker by global gene expression analysis. Nat Med 11: 481-483.

Porter S, Clark IM, Kevorkian L, Edwards DR. 2005. The ADAMTS metalloproteinases. Biochem J 386: 15-27.

Price JT, Tiganis T, Agarwal A, Djakiew D, Thompson EW. 1999. Epidermal growth factor promotes MDA-MB-231 breast cancer cell migration through a phosphatidylinositol $3^{\prime}$ kinase and phospholipase c-dependent mechanism. Cancer Res 59: 5475-5478.

Rae J, Creighton C, Meck J, Haddad B, Johnson M. 2007. MDAMB-435 cells are derived from M14 Melanoma cells-A loss for breast cancer, but a boon for melanoma research. Breast Cancer Res Treat 104: 13-19.

Reponen P, Sahlberg C, Munaut C, Thesleff I, Tryggvason K. 1994. High expression of $92-\mathrm{kDa}$ type IV collagenase (gelatinase) in the osteoclast lineage during mouse development. Ann N Y Acad Sci 732: 472-475.

Rood PML, Calafat J, Von dem Borne AEGK, Gerritsen WR, van der Schoot CE. 2000. Immortalisation of human bone marrow endothelial cells: Characterisation of new cell lines. Eur J Clin Invest 30: 618-629.

Roodman GD. 2004. Mechanisms of bone metastasis. N Enl J Med 350: 1655-1664.

Rucci N, Ricevuto E, Ficorella C, Longo M, Perez M, Di Giacinto C, Funari A, Teti A, Migliaccio S. 2004. In vivo bone metastases, osteoclastogenic ability, and phenotypic characterization of human breast cancer cells. Bone 34: 697709.

Takahashi N, MacDonald BR, Hon J, Winkler ME, Derynck R, Mundy GR, Roodman GD. 1986. Recombinant human transforming growth factor- $\alpha$ stimulates the formation of osteoclast-like cells in long-term human marrow cultures. J Clin Invest 78: 894-898.

Tanaka S, Takahashi T, Takayanagi $\mathrm{H}$, Miyazaki T, Oda $\mathrm{H}$, Nakamura K, Hirai H, Kurokawa T. 1998. Modulation of osteoclast function by adenovirus vector-induced epidermal growth factor receptor. I Bone Miner Res 13: 1714-1720.

Tezuka K, Nemoto K, Tezuka Y, Sato T, Ikeda Y, Kobori M, Kawashima H, Eguchi H, Hakeda Y, Kumegawa M. 1994. Identification of matrix metalloproteinase 9 in rabbit osteoclasts. J Biol Chem 269: 15006-15009. 
Lu et al.

Thompson DL, Lum KD, Nygaard SC, Kuestner RE, Kelly KA, Gimble JM, Moore EE. 1998. The derivation and characterization of stromal cell lines from the bone marrow of $\mathrm{p} 53^{-/-}$ mice: New insights into osteoblast and adipocyte differentiation. J Bone Miner Res 13: 195-204.

von Minckwitz G, Jonat W, Beckmann M, De Bois A, Kleeberg U, Kuhnie H, Kettner E, Hilfrich J, Torode J, Schneeweiss A. 2003. A multicenter phase II trial to evaluate gefitinib (Iressa, ZD1839) (500mg/day) in patients with metastatic breast cancer after previous chemotherapy treatment. Eur I Cancer 1: $\mathrm{S} 133$.

Wakeling AE, Guy SP, Woodburn JR, Ashton SE, Curry BJ, Barker AJ, Gibson KH. 2002. ZD1839 (Iressa): An orally active inhibitor of epidermal growth factor signaling with potential for cancer therapy. Cancer Res 62: 5749-5754.

Wang K, Yamamoto H, Chin JR, Werb Z, Vu TH. 2004. Epidermal growth factor receptor-deficient mice have delayed primary endochondral ossification because of defective osteoclast recruitment. I Biol Chem 279: 5384853856.

Weber MH, Lee J, Orr FW. 2002. The effect of Neovastat (AE941) on an experimental metastatic bone tumor model. Int $J$ Oncol 20: 299-303.

Winding B, NicAmhlaoibh R, Misander H, Hoegh-Andersen P, Andersen TL, Holst-Hansen C, Heegaard AM, Foged NT, Brunner N, Delaisse JM. 2002. Synthetic matrix metalloproteinase inhibitors inhibit growth of established breast cancer osteolytic lesions and prolong survival in mice. Clin Cancer Res 8: 1932-1939.

Yin JJ, Mohammad KS, Kakonen SM, Harris S, Wu-Wong JR, Wessale JL, Padley RJ, Garrett IR, Chirgwin JM, Guise TA. 2003. A causal role for endothelin-1 in the pathogenesis of osteoblastic bone metastases. Proc Natl Acad Sci 100: 10954-10959.

Yoneda T, Sasaki A, Dunstan C, Williams PJ, Bauss F, De Clerck YA, Mundy GR. 1997. Inhibition of osteolytic bone metastasis of breast cancer by combined treatment with the bisphosphonate ibandronate and tissue inhibitor of the matrix metalloproteinase-2. J Clin Invest 99: 2509-2517.

Zhu J, Jia X, Xiao G, Kang Y, Partridge NC, Qin L. 2007. EGFlike ligands stimulate osteoclastogenesis by regulating expression of osteoclast regulatory factors by osteoblasts. J Biol Chem 282: 26656-26664. 


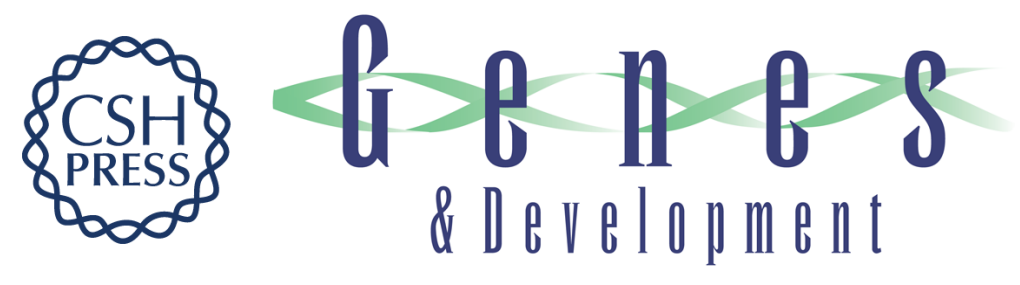

\section{ADAMTS1 and MMP1 proteolytically engage EGF-like ligands in an osteolytic signaling cascade for bone metastasis}

Xin Lu, Qiongqing Wang, Guohong Hu, et al.

Genes Dev. 2009, 23: originally published online July 16, 2009

Access the most recent version at doi:10.1101/gad.1824809

\section{Supplemental http://genesdev.cshlp.org/content/suppl/2009/07/17/gad.1824809.DC1 \\ Material}

Related Content Breaking down bone: new insight into site-specific mechanisms of breast cancer osteolysis mediated by metalloproteinases

Theresa A. Guise

Genes Dev. September , 2009 23: 2117-2123

References This article cites 57 articles, 18 of which can be accessed free at: http://genesdev.cshlp.org/content/23/16/1882.full.html\#ref-list-1

Articles cited in:

http://genesdev.cshlp.org/content/23/16/1882.full.html\#related-urls

\section{License}

Email Alerting

Service

Receive free email alerts when new articles cite this article - sign up in the box at the top right corner of the article or click here.

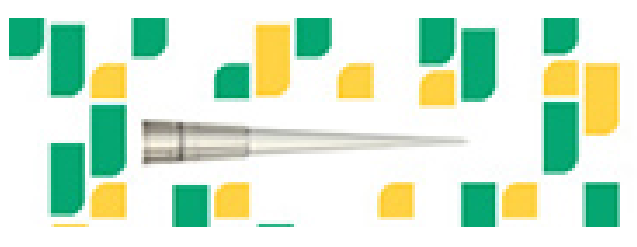

Focused on your science. 